\title{
¿Por qué la gente compra fayuca en los tianguis de Monterrey?*
}

\section{Why do people purchase fayuca in Monterrey's tianguis?}

\author{
EFRÉN SANDOVAL HERNÁNDEZ**
}

\begin{abstract}
This article aims to show that the purchase of fayuca, or contraband, in the tianguis, or street markets, happens because it serves to sustain social ties and, particularly, the social practice of the family. The text uses the literature on social practices and consumption to make such a demonstration. The information comes from observations, dialogues, interviews and focus groups, conducted mainly with women who regularly attend the tianguis in Monterrey. The results show that people buy items to use in the elaboration and reproduction of social practices they consider important, and that for this the fayuca is highly functional because it is cheap, very accessible and abundant. The article is original because, unlike most of the literature on the informal economy, it focuses on consumption, although it does not cover the diversity of consumers who come to the market.
\end{abstract}

Key words: Consumption, social practices, informal economy, smuggled goods, street markets, used clothing

\begin{abstract}
Resumen
El objetivo de este artículo es demostrar que la compra de fayuca en los tianguis sucede porque sirve para sostener vínculos sociales y con ello la práctica social de la familia. Para tal fin, se recurre a la literatura sobre prácticas sociales y consumo. La información se obtuvo de observaciones, diálogos, grupos focales y entrevistas realizadas sobre todo con mujeres que de manera habitual acuden a los tianguis en Monterrey. Los resultados permiten afirmar que las personas adquieren artículos para utilizarlos en la elaboración y reproducción de las prácticas sociales que consideran importantes y que, para ello, la fayuca es altamente funcional, porque es barata, muy accesible y abundante. El artículo es original porque, a diferencia de la mayor parte de la literatura sobre la economía informal, éste se centra en el consumo, aunque no abarca a la diversidad de consumidores que acuden al tianguis.

Palabras clave: consumo, prácticas sociales, economía informal, mercancías de contrabando, mercados rodantes, ropa usada
\end{abstract}

\section{Introducción}

$\mathrm{E}$ ste artículo es resultado de una investigación sobre el comercio de fayuca en los tianguis de Monterrey. En términos empíricos, entiendo por fayuca las mercancías baratas (chácharas), sobrantes (saldos) y usadas introducidas como contrabando por la frontera norte de México y luego vendidas en los mercaditos (término común en la capital de Nuevo León para referirse a los tianguis). A esas mercancías, sobre todo en su calidad de

\footnotetext{
* Artículo recibido el 13/02/20 y aceptado el 08/04/20.

** Centro de Investigaciones y Estudios Superiores en Antropología Social, Unidad Noreste. Prolongación José María Morelos 822, Barrio Antiguo, 64000 Monterrey, N. L. <esandoval@ciesas.edu.mx>. ORCID: 0000-0002-2706-9388.
} 
baratas y sobrantes, se agregan otras provenientes de centros de abastecimiento de mercancías legal e ilegalmente importadas, como Colegio Civil (en Monterrey), Tepito y Mercado de Sonora (en la Ciudad de México) o San Juan de Dios (en Guadalajara).

En la segunda mitad del siglo xx, el término fayuca fue utilizado para referirse a las mercancías de contrabando (electrónicos, perfumes, enseres, ropa y alimentos no perecederos) venidas desde Estados Unidos. Hoy casi nadie utiliza el término, no obstante se siguen comercializando de manera informal muchas mercancías introducidas sin reporte por las fronteras y los puertos. A estas mercancías son a las que, para los fines de mi investigación, llamo fayuca. Ésta, en el caso del área metropolitana de Monterrey, es comercializada principalmente en tianguis.

En términos analíticos, la comercialización y el consumo de fayuca forma parte del proceso globalizador propio de la sociedad actual. Constituida sobre todo por mercancías baratas (chácharas), sobrantes (saldos) y desechadas (usadas), la fayuca representa la abundancia de mercancías (Gill, 2009) en un modo de producción donde el consumo jala a la producción y no a la inversa (Bonacich, cit. por Lichtenstein, 2006: 30), y donde, para reproducirse, muchas condiciones de la vida cotidiana requieren de la adquisición y el intercambio de mercancías y servicios (Harvey, 2013: 93). La mayoría de las mercancías usadas y saldos provienen de los desechos generados por los consumidores estadounidenses, y de los sobrantes de los también estadounidenses almacenes minoristas, mismos que, juntos, comercializan cada día millones de artículos fabricados especialmente en Asia. A estos productos se agregan aquellos que llegan directo desde aquel continente hasta México, vía los puertos marítimos y grandes centros de distribución como Tepito. Aunque con sus peculiaridades, los consumidores de fayuca en México, sean éstos de medianos o bajos ingresos, están inmersos en intensas dinámicas de consumo propias de las sociedades mercantilizadas.

Aquí demuestro que la compra de fayuca es un acto que forma parte de prácticas sociales diversas dentro de las cuales predomina lo que llamo la práctica de la familia o familismo. La gente compra fayuca porque las mercancías en general, y la fayuca en particular, funcionan para aquello que realmente le interesa, es decir, sostener vínculos. Y dentro de la muy amplia maraña de vínculos que la gente establece y recrea son fundamentales aquellos sostenidos con los parientes. Esta es la razón que casi siempre le da sentido a la compra de fayuca, aunque no significa que no haya otras en el marco de la diversidad de consumidores que acuden a los tianguis (sobre ello reflexiono en las conclusiones). En este marco, explicaré primero a qué me refiero con la idea de prácticas sociales y práctica de la familia. Después, utilizaré información empírica derivada de observaciones, diálogos y entrevistas individuales, así como de grupos focales, con consumidoras que con asiduidad acuden a los tianguis.

\section{Las compras, una práctica social}

La abundancia de mercancías y el consumo de masas tienen sus bases en los altos volúmenes de producción, los bajos costos y la rápida circulación de mercancías. Esta última equivale a deshacerse de los artículos, sea vendiéndolos o desechándolos (que en muchos casos es otra forma de venderlos). Hoy, casi cualquier empresario o comerciante minorista entiende que el capital en lugar de desperdiciarse en mercancías que tardan mucho en venderse puede invertirse en cosas que la gente compra sólo porque son baratas, y que pueden hacerse fortunas no a través del encarecimiento de los artículos sino aumentando la circulación de mercancías, los volúmenes de ventas de productos baratos y las economías de escala (Strasser, 2006: 66-67). Para lograr lo anterior no sólo hay que vaciar los anaqueles de todo aquello que no fue vendido y volverlos a llenar, tampoco es suficiente con beneficiar a los mercados residuales (circuitos de saldos, recicladores), sino que es imperativo que los consumidores crean que, $a$ ) aquello que compraron en el pasado inmediato está obsoleto no porque ya no funcione o se haya acabado, sino porque parece menos atractivo que otro que puede adquirirse en un nuevo acto de compra (Ewen, 1991); y b) que se tiene la posibilidad de hacerse de un artículo tan barato que no importa mucho gastar un poco más por él, y tampoco si éste es en realidad necesario o no. Se trata, en palabras de Strasser (2006: 59), de productos que todos pueden utilizar y todos pueden pagar. La posibilidad de comprar, de poseer algo nuevo (en el sentido de recientemente adquirido) se funda como el motivo central de una acción que deviene cotidiana y banal. Pero, el hecho de que la práctica de comprar algo pueda ser trivial no supone que la práctica social a la cual tal acto es funcional no tenga un gran significado para quien realiza el acto de comprar. De hecho, aquí la propuesta es que pasa justo lo contrario, es decir, el acto banal de comprar resulta trascendental para la reproducción de prácticas sociales que a su vez son absolutamente relevantes para quienes compran. Debido a que muchas prácticas suceden en el marco de sociedades mercantilizadas, sostengo que lo antes dicho es compartido por todos los consumidores, sean 
clasemedieros londinenses o habitantes de un barrio de clase media baja de Monterrey. Para eso, empiezo por insistir en la diferencia entre una práctica y una práctica social.

De acuerdo con Reckwitz (2002: 249), práctica se refiere a toda acción humana en un sentido descriptivo, mientras que prácticas sociales es un término teórico que se enfoca en acciones como comportamientos corporales, actitudes mentales, conocimientos compartidos, principios de entendimiento, formas de hacer, estados emocionales, conocimientos motivacionales, y la implicación en ello de objetos o elementos no humanos. Es decir, las prácticas sociales engloban conocimientos, procedimientos y compromisos (Warde, 2005: 134), de modo tal que la gente hace algo porque sabe cómo, cuándo, dónde y por qué se hace; lo hace porque sabe lo que significa hacerlo y cuáles son las consecuencias esperadas de realizarlo. Así, debido a que todo lo conocido por el actuante existe antes de que éste lo aprenda, cuando el actor hace hay algo que se recrea a nivel social, y en esa recreación la gente está involucrada en el sentido de desear, buscar, procurar o esperar que suceda tal recreación de las cosas. Eso que se recrea es lo que aquí -con base en Giddens (2003)- llamo prácticas sociales. Es en este tenor que planteo: la gente va a comprar fayuca al mercadito, pero ¿qué es lo que socialmente se recrea cuando la gente compra fayuca en el mercadito?

El acto de comprar sirve en la organización de algo más, ${ }^{1}$ a lo cual llamo práctica social, así: "es el acto del involucramiento en la práctica [social], más que ningún deseo personal sobre una conducta, el que explica la naturaleza y el proceso del consumo" (Warde, 2005: 138). La práctica social proporciona entonces la justificación, la necesidad, el deseo o el gusto por comprar una mercancía en un mercado. Y en el marco de las observaciones realizadas y los testimonios recabados en el trabajo de campo, sostengo que comprar fayuca es una de las maneras en que se organiza la familia como práctica social o, en otras palabras: las personas compran fayuca como una forma de recrear la práctica social de la familia. Del involucramiento en tal recreación, y no del consumo de mercancías, las personas obtienen recompensas, las cuales pueden ser muy diversas y estar relacionadas con infinidad de circunstancias, pero en general tendrán que ver con dos: a) refrendar la pertenencia a la práctica social al participar en ella, y entonces esperar el reconocimiento como participante por parte de otros que también intervienen, y b) "influir" en aquellos con quienes comparte los bienes de consumo (como regalos) "para que se conviertan en el tipo de persona que sería el receptor apropiado para aquello que está comprando" (Miller, 1999: 22), es decir, comprometer a otra persona mediante una acción (por ejemplo un regalo), para que se comporte de una forma esperada. De este modo, quien compra para otros está enviando el mensaje: "aquí estoy, sigo siendo parte de nuestro lazo social, espero que tú también lo sigas siendo".

Tal y como mostraré, con frecuencia, la gente compra fayuca pensando en otros a quienes les regalará o con quienes compartirá aquello que adquiere. Claro que cuando el miembro de una familia compra algo para otro miembro de la misma familia no lo hace pensando en la obligación del otro de devolver, pues esto sería tanto como degradar la relación (Mauss, 1995), en cambio, muchas de las compras aparecen como logros (en el sentido de hallazgos casi heroicos o derivados de conocimientos expertos) (Parsons, 2007: 392), como "agasajos" (es decir, como un gusto o algo especial) (Miller, 1999: 59-60), o como necesidades que, cumplida y responsablemente, se cubren.

\section{Las compras, un asunto de familia}

Como dije, la fayuca está conformada, en principio, por mercancías de contrabando que, a su vez, son en su mayoría artículos baratos (chácharas), sobrantes (saldos) y desechados (usados). De las tres características mencionadas, acaso la primera es positiva cuando se le toma en su sentido de ahorro, pero incluso ésta puede ser tomada como negativa cuando hace referencia a la escasa calidad de un artículo o a su menor calidad con relación a otro. Si éste es el caso, y si al mismo tiempo abundan los artículos baratos y nuevos tanto en el mercadito como en muchos otros lugares a los cuales se puede acudir a comprar, entonces ¿por qué la gente compra fayuca? y ¿por qué compra fayuca para regalarla a la familia?, cuando se supone que los objetos que se regalan deben ser valiosos. Responderé a estas preguntas a partir de dos vertientes, una que va más en el sentido de por qué no se compran las cosas nuevas y duraderas, y otra que dirige la mirada hacia la práctica social de la familia y la relevancia que en ella tiene la compra de mercancías baratas, usadas o sobrantes. En ambos casos parto del supuesto de que la respuesta a por qué la gente compra cosas baratas

1 Para Miller (1999: 17), las compras "son un medio para descubrir, a través de la estrecha observación de las prácticas de la gente, algo acerca de sus relaciones". 


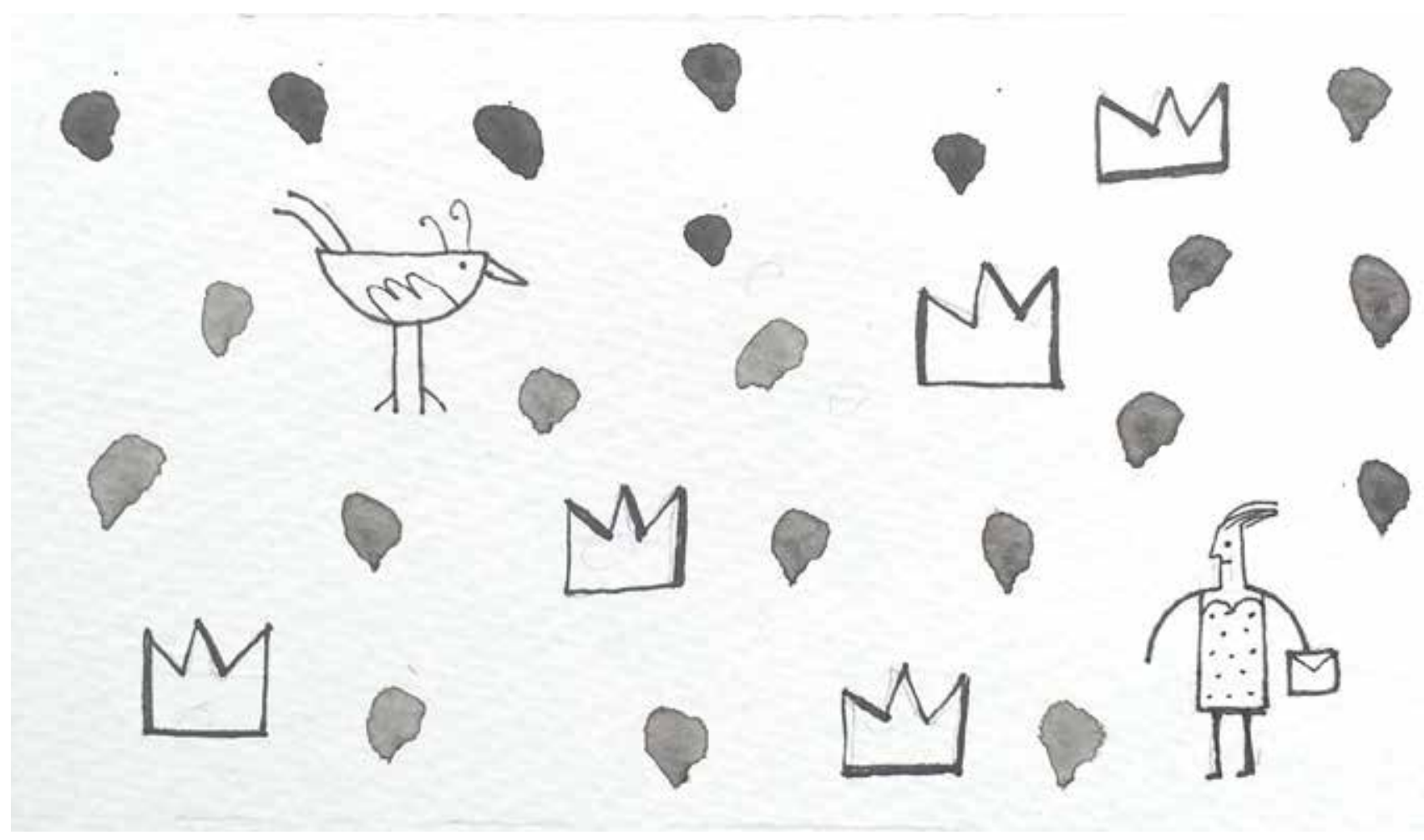

no tiene que ver necesariamente con una condición económica que, aunque es real en muchos casos, no es concluyente; es decir, no sólo se compran cosas baratas porque no se tienen los recursos económicos para adquirir cosas más caras.

La primera vertiente a la que me refiero en el párrafo anterior parte del supuesto de que el consumidor, más que actuar como un sujeto aislado, que desde una posición individual se encuentra frente a una mercancía y un medio (como la publicidad o la moda) que lo incita a comprar, es un sujeto que experimenta el mundo a través de su pertenencia a prácticas sociales las cuales tienen "sus propias convenciones institucionalizadas y colectivamente reguladas”. Esto es, más que estar aislado ante el mercado, el individuo es aislado por las prácticas sociales en relación con "los halagos de los productores y agencias publicitarias" (Warde, 2005: 141), y por ello puede entenderse que, más que sucumbir de un modo iluso ante las novedades y las tendencias publicitadas, el consumidor seleccione aquello que compra a partir de criterios que primero tienen que ver con cuestiones distintas a lo que, según los publicistas, le ofrece la adquisición de un artículo.
Así, por ejemplo, la distinción -elemento aludido casi como lugar común en cuanto argumento esencial de venta de los publicistas y la primordial razón por la cual la gente adquiere mercancías-, queda en un plano secundario cuando de lo que se trata es de perpetuar relaciones o demostrar el involucramiento en un grupo social (Duffy, Hewer y Wilson, 2012). ${ }^{2}$ La hipótesis de la distinción también encuentra problemas cuando se piensa que un artículo usado es preferible sobre uno nuevo o que al momento de ofrecer un regalo se haga con un objeto barato y no con uno de mayor valía. ${ }^{3}$

Si se considera al consumidor en cuanto que sujeto involucrado en prácticas sociales, entonces las compras aparecen más bien como una de las formas en que las personas buscan involucrarse o permanecer involucradas en prácticas sociales. Esto significa que las compras son funcionales a las prácticas sociales, y no representan la sumisión de los consumidores ante el mercado, ya que las prácticas sociales permanecen bajo el control de las personas, pues ellas deciden cuáles son las prácticas trascendentes en su vida. Y, en algunos lugares, como en Monterrey, la práctica de la familia puede ser más importante que en otros, así

2 Para, Miller (1999: 17), "las compras están dominadas por lo que se imagina acerca de otros, acerca de lo que desean de usted y de la respuesta que le darán".

3 Y si se toma la distinción tal y como la propone Bourdieu (1998) también se hallarían problemas, pues supone que todos los consumidores practican el habitus de la búsqueda de superación de su posición en el campo del gusto (moda), dejando fuera, entre otros, a aquellos consumidores que están implicados en otros campos cuyo capital principal está lejos de ser la distinción. 
como algunas prácticas sociales que aquí son irrelevantes en otro lugar pueden resultar primordiales para las personas, tal y como se verá más adelante con el caso de la ropa usada.

\section{Ir de compras al mercadito}

El trabajo de campo -consistente en instalarme como tianguista, en diálogos y observaciones con vendedores y consumidores, así como en grupos focales con quienes gustan de ir a comprar al mercadito-arrojó que la mayoría de los consumidores del tianguis son mujeres. $\mathrm{Al}$ respecto, diversos estudios han demostrado que son las mujeres quienes primordialmente llevan a cabo las compras que funcionan como aprovisionamiento para los miembros de una familia (Arvanitidou y Gasouka, 2013; Koca, Vural y Koç, 2013), lo cual incluye, además de los alimentos, artículos como la ropa.

Aunque en la mayoría de las sociedades el acto de comprar es considerado, en principio, moralmente malo, pues se concibe como un gasto y por ende como una pérdida, de acuerdo con Miller (1999), por lo común las compras son justificadas o explicadas por los consumidores como algo positivo. De esto se derivan dos cosas. La primera es que, más que como un gasto, las compras deben aparecer como una forma de ahorro, y para ello se recrea un "discurso sobre las compras"; la segunda es que, la razón de ser de las compras a menudo tiene que ver con cariños, cuidados, preocupaciones, atenciones o "amor". En este marco, pude entender la excitación o emoción con que algunas consumidoras hablan sobre los artículos que adquirieron en el mercadito, y la referencia a su bajo precio en relación con su buena calidad o con el costo en una tienda departamental. Las compras aparecen como logros y buenas acciones para las prácticas que realmente le interesan a la gente, piénsese en la armonía familiar, la educación de los hijos o la relación con la comunidad (el vecindario, por ejemplo).

Las compras en el mercadito, a través de las mercancías baratas, usadas y sobrantes, son, parafra- seando a Miller (1999: 34) en su explicación sobre las compras por amor, una de las principales maneras de manifestar y reproducir los vínculos personales en los que están comprometidas las personas. Aquí, se trata de "una práctica de relaciones de largo plazo" con "una ideología normativa" que implica obligaciones y responsabilidades, y no sólo "alguna visión romántica" (Miller, 1999: 34) sobre, en este caso, la familia o las amistades. Es decir, no hay que tomar a la práctica de la familia como algo necesariamente armonioso y sentimental, es, en cambio, una práctica que consiste en involucrar a la familia en las cosas de la vida (trabajar, comer, pasar el tiempo libre, cuidar, o practicar una creencia religiosa, entre otras); pero también ejercer un conflicto, competir, rivalizar o tomar partido por alguien. Todo esto se hace en familia o incluye a la familia, y difícilmente puede suceder de otra forma. Se trata, dicho en palabras de Ariza y de Oliveira (2004: 36), de "la opción de vida familiar como eje de la trayectoria personal para un subconjunto de la población". En todas estas relaciones, los objetos, entre ellos las mercancías que se compran en un tianguis, con frecuencia hacen las veces de mensajes o de medios en una práctica social que, para mucha gente, está por encima de un sinfín de cálculos pragmáticos a la hora de hacer las compras, e incluso funciona como un valor moral casi trascendente (Miller, 1999: 35). Así, la fayuca, en cuanto que conjunto de mercancías, aparece como una oportunidad muy a la mano para refrendar aquello que interesa refrendar.

\section{Por qué vamos al mercadito}

De acuerdo con la información recabada en tres grupos focales con consumidoras de mercaditos, ${ }^{4} \mathrm{y}$ en conversaciones informales con consumidores, hay tres motivos esenciales por los cuales la gente acude al tianguis. El primero es económico, y tiene que ver con lo barato de las mercancías; el segundo es lúdico: al mercadito se acude para pasear; ${ }^{5}$ el tercero se relaciona con la alimentación: al tianguis se va a comer en los puestos de comida preparada.

\footnotetext{
4 Las reuniones de los tres grupos focales se llevaron a cabo en el verano de 2018. Los grupos estaban diferenciados por nivel económico y por su ubicación en diferentes sectores geográficos de la ciudad. Dos de ellos fueron considerados de ingreso medio bajo y uno de ingreso medio. Los de ingreso bajo estuvieron constituidos por mujeres que son amas de casa o que laboran como empleadas de limpieza en oficinas o en casas. Una de ellas se instalaba cada semana en un tianguis cobrando por el uso de juegos infantiles (brincolines). Todas están casadas y sus esposos tienen empleos tales como la soldadura, la albañilería o el transporte público (chofer). Uno de los grupos de bajo ingreso se ubicó en el municipio de Guadalupe (en el área metropolitana de Monterrey, Амм), y el otro en el de Monterrey. Por último, el grupo caracterizado de ingreso medio estuvo integrado por mujeres que habitan en el municipio de San Nicolás de los Garza, al norte del Amm, en una zona típica de clase media, con casas con cochera para un vehículo en terrenos de aproximadamente $90 \mathrm{~m}^{2}$. Ninguna de ellas trabaja. La mayoría estaban casadas y sus maridos eran pequeños comerciantes y empleados.

5 El carácter lúdico de la visita al tianguis, en Monterrey, es destacado también por Rubio Campos (2015).
} 
Los motivos no son excluyentes entre sí. Si el objetivo es comer se adquiere algo en el camino o, si se va a pasear, algo se comprará; de igual modo, si el propósito es hacer compras, se aprovecha para comer algo, para pasear, y para hacerse de algo que no se tenía planeado comprar.

El tianguis se usa como un espacio para adquirir mercancías y para la convivencia y el esparcimiento, actividades todas que, al final, sirven para la recreación de la misma práctica social: la familia y, en otros casos, las amistades. Al respecto, la señora Tatiana me comentó: "Mi hermana y yo nos acompañamos, y tenemos cuatro amigas con las que siempre vamos: Aurora, Rosa, Paty y Dominga, ah, y Mary". Para Tatiana, ir al mercadito es: "desestresarme, porque hay mucha convivencia, mucha plática con las personas que conocemos y nos vamos a desestresar ahí, porque mi hermana y yo estamos en la casa toda la semana... para nosotros es un relax ir ahí". ${ }^{6}$

Cuando a la gente se le pregunta por qué va al mercado contesta que va a buscar cosas baratas (motivo económico), frecuentemente ropa (en su mayoría usada) y chácharas (artículos varios, baratijas, cosas sin mucha relevancia), o para comer "algo":

A mi esposo y a mí nos gusta ir a mercadear porque compras cosas de muy buena calidad, muy económicas... venden ropa nueva americana muy barata, mucho más barata que en Estados Unidos. Yo he comprado allá y luego vengo aquí y en el mercadito me la encuentro la misma calidad, la misma marca y muchísimo más barata... ${ }^{7}$

Si vas al mercadito, compras una blusa que ocupas. El mercadito te la va a dar en 15 pesos, y si vas al centro, la vas a comprar en 80 pesos... es ahorrarte tiempo y... dinero... Tiempo porque de aquí tienes que salir al centro y luego caminar todo el centro, y de aquí al mercadito son dos, tres cuadras y no gastas en transporte y nada más gastas lo del mercadito. ${ }^{8}$

Entre las mercancías que se consiguen a mejor precio en el tianguis están la ropa y el calzado (en especial deportivo), la fruta y la verdura. Además de la comida preparada, son productos que "siempre se pueden encontrar en el mercadito". Otras mercancías que también se adquieren en el tianguis por ser más económicas que en otros lugares son juguetes, joyería de fantasía, bolsas para dama, cosméticos, herramientas, perfumes y licores, así como artículos para celulares. Algunos de estos productos pueden comprarse nuevos o usados (ropa, juguetes, bolsas, herramientas, artículos para celulares), y todos pueden considerarse fayuca por ser fruto del contrabando en la frontera, ya sean nuevos (ropa, juguetes, joyería, bolsas, perfumes), chácharas (juguetes, joyas, cosméticos, artículos para celulares), usados (ropa, juguetes, bolsas, herramientas) o saldos (ropa, joyería, herramientas, electrodomésticos, juguetes).

En todos los casos, la gente entrevistada emplea un "discurso de las compras" (Miller, 1999) que la posiciona como buena compradora en el sentido de dominar la habilidad de conseguir buenos precios. Esto pasa por tener claro cuáles son los mejores mercados, quiénes son los mejores vendedores y dónde están las mejores mercancías:

La señora Rosa vende ropa de bebé y para la familia. Es nueva, de marca y precios bien accesibles. Entre las marcas que recuerdo [están] Old Nave y Colts. La señora Mary trae ropa de Macy's, con ella tengo muchos años de comprar... consigue cosas muy buenas. Con ellas generalmente es ropa y adornos para el hogar, cosas que encuentras en, por ejemplo, en tiendas prestigiadas de Estados Unidos. La señora Aurora trae de una tienda que... es de Houston... Ikea, pero sí, encuentras cosas muy finas. La señora Paty vende ropa nueva, nosotras no compramos ropa usada. La señora Diana es adornos para la casa, de Home Interiors. Ellas son las oferentes con las que más compramos, nos inclinamos más por las cosas que realmente necesitamos y por las personas con las que nos acomodamos en la cuestión económica, porque habrá personas que sí tengan dinero para ir a gastar miles de pesos, pero [nosotras] no. ${ }^{9}$

Esto, dicho sea de paso, señala una explicación del gusto por ir al mercadito, pues el hecho de "encontrar" buenos precios, conlleva la acción de "buscar" en el sentido de seleccionar y no tanto de "conseguir" algo que se necesita. Ir a buscar gangas en el mercadito es más un signo de libertad que de necesidad, de ahí que se encuentre placer en ello (Stebbins, 2006) y que, en medio de la abundancia de mercancías, las personas se conviertan en especialistas en la búsqueda de objetos particulares, o se otorguen el permiso de comprar cosas que no les hacen falta.

Carolina me había dicho que ocupaba unos pantalones blancos, pero en el mercadito no es lo que estás buscando

\footnotetext{
6 Entrevista a Tatiana, 16 de mayo de 2011.

7 Grupo focal de San Nicolás de los Garza (en adelante GFSN), 18 de junio de 2018.

8 Grupo focal de Monterrey (en adelante GFM), 13 de junio de 2018.

9 Entrevista a Tatiana, 16 de mayo de 2011.
} 
sino lo que encuentras, pero esta ocasión me fue muy bien. También mi esposo a veces me dice... quiero una camisa beige, una camisa blanca. Oye, espérame, le digo, ahí no es Liverpool, pero él me contesta: 'no, sólo para que, si ves algo así, pues me lo compres. ${ }^{10}$

Mi esposo andaba por un ladoy yo por el otro, y él buscando fierros o cosas que le hacían falta, o más bien, que no le hacían falta, pero él se las traía porque estaban baratas. ${ }^{11}$

En el mercadito me emociona porque está muy barato y entonces compro más. Me he comprado ropa... relojes... collarcitos... cosméticos, porque también salen como lotes, o no sé cómo los consigan o qué, pero buena marca y cerrados y todo. ${ }^{12}$

Casi siempre venimos con el señor que vende los hilos porque trae variedad. Trae... hilos y agujas de todos los números. Le compré del 1, 2, 3, y de chaquira. No sé por qué compré de chaquira si no la uso, pero me dio tentación, le dije, me da esos de chaquira, y un paquetillo de agujas. Tengo agujas de todos tamaños, y todas las compré en la barata. ${ }^{13}$

Dije, -mira Rodolfo, esa señora tiene dos bolsas de esas grandotas que a mí me gustan para echar muchas cosas... me gustó.

—Señora ¿cuánto las da?

-Veinte pesos

Y me dijo mi esposo, - llévate las dos, y le digo —¿me las compras? y él, —sí': 40 pesos.

Ayer me encontré una amiga y me dijo: —qué bonita bolsa, y es de marca. Y yo le dije, —pues no sé si es de marca o no, pero me gustó.

—¿Dónde la compraste?

Le dije: - pues me la dieron a 20 pesos en el mercadito. — No lo puedo creer porque ésta es de marca!

—Ay!, pues yo no sé de marcas, yo las compré porque me gust[aron]. ${ }^{14}$

Las compras superfluas se suponen propias de las clases más adineradas, sin embargo, el mercadito representa un espacio de oportunidad para el hedonismo, pero, en el caso de análisis, no tiene que ver con la aspiración de ser como otros (los "ricos", como se les llama entre las entrevistadas), sino con el hecho de encontrar, en medio de las constricciones materiales que se padezcan, un espacio de placer relativo, eso sí, a las prácticas sociales que son importantes para cada uno. Entonces, esas recompensas o logros objetivados en las mercancías baratas son compartidos con las personas que en verdad interesan a los consumidores. Y aunque muchas mercancías del mercadito son de segunda mano se convierten en regalos, e incluso superan a las adquiridas para uso personal (en una relación de quince contra nueve):

Entrevistada: Pita compra para todos, para la familia, para los sobrinos, para los tíos, para los primos, hasta me ha tocado a mí que me trae.

Pita: Es que si veo una falda que está en cinco pesos, yo sé que mi hermana la va a usar o alguien de la familia la va a usar: "ésta le queda a fulanita", y yo les compro porque está barato, que a tres pesos que a cinco pesos, y me dice mi hermana: "oye, tu siempre compras muy buenas cosas", por eso compro para todos, porque si fuera muy caro no podría comprar todas [las cosas que compro] ¿Verdad? que tres, que cinco, que diez, y me traigo varias piezas". ${ }^{15}$

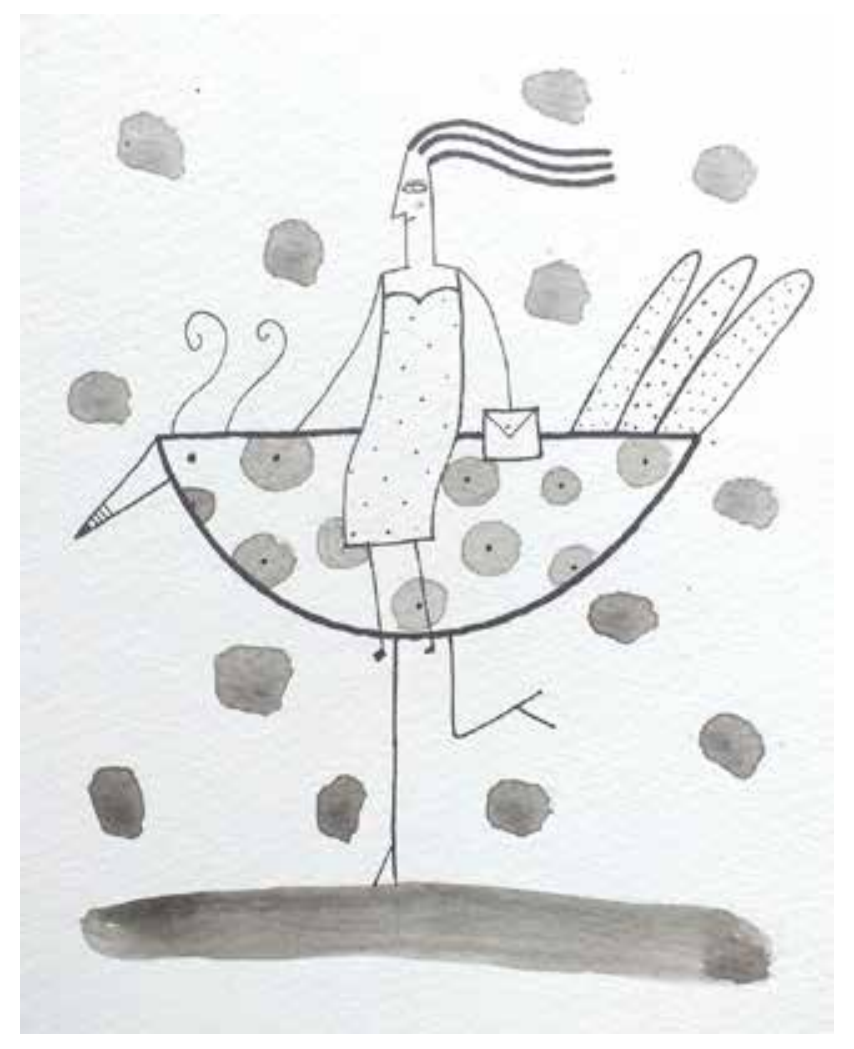

${ }^{10}$ Entrevista a Norma, 24 de abril de 2018.

${ }^{11}$ GFSN, 19 de julio de 2018.

12 GFSN, 19 de julio de 2018.

13 GFM, 13 de julio de 2018.

14 GFM, 13 de julio de 2018 .

15 GFM, 13 de julio de 2018. 
Los niños son un destinatario importante de las mercancías compradas "para la familia". En las experiencias de trabajo de campo en los puestos de venta fue interesante observar que entre los artículos más fáciles de vender estaban los de los niños, sin importar si se trataba de juguetes o de prendas de vestir nuevas o usadas. ${ }^{16} \mathrm{Al}$ respecto, hay un cierto "discurso sobre las compras" (Miller, 1999):

tengo el niño que a cada rato ocupa ropa nueva [de mayor talla], pues me voy a comprarle cambios de ropa en el mercadito. Digo, le voy a comprar allá porque aquí [en un almacén de venta de ropa nueva] un cambio [es] de 300 pesos, y la va a dejar de usar en seis meses, y acá un cambio en 50 pesos, pues igual lo va a dejar en seis meses. ${ }^{17}$

el año pasado me aventé con mi niño cada dos meses comprándole ropa y zapatos. Tengo uno de 15 [años] y en un año creció bastante... cada dos o tres meses, que otra talla de pantalón, y que camisas de [otra] talla. ${ }^{18}$

Pero el trabajo de campo brindó la experiencia de contrastar lo dicho con lo hecho al evidenciar que hay muchas razones (o sinrazones) por las cuales se compra a los niños. Así, en un diario de campo, reporté:

Vendí tres juguetes de Luis, uno, a unos abuelos que querían algo para su nieto de dos años, pero terminaron comprando algo para los nietos un poco más grandes, "para que se entretengan". Otro fue de dos señoras que iban con sus hijos y que claramente les compraron algo barato, así como que por comprarles algo, supongo que en el contexto de que ellas ya se habían comprado algo, pues ya llevaban mercancías en unas bolsas. ${ }^{19}$

Y el testimonio del padre de una niña a la que, como a cualquier otra, le gustan mucho los juguetes, revela lo siguiente:

A mi hija le gustan mucho los puestos con juguetitos de todo tipo, pero entre ella y su mamá tienen un acuerdo... ella puede ver todos los puestos de juguetes siempre y cuando no le pida que se los compre. Sólo toma el juguete y dice: "mira, mami, una pelotita”, y así sucesivamente. Sólo en algunas ocasiones le compramos algo... por lo general no son juguetes caros, ya que los nuevos valen alrededor de 25 a 40 pesos, y los usados entre cinco y 20 pesos. ${ }^{20}$

Al acompañar a un vendedor de artículos usados dentro de los cuales destacan los juguetes, un asistente mencionó cómo muchas de las compras para los menores no son de cosas nuevas, buscando alguna compensación en el comportamiento, lo que se hace es aprovechar el bajo precio de algunos juguetes:

Al inicio llegó una señora con sus tres hijos. De inmediato preguntó por un dragón con alas.

Cliente: ¿Cuánto cuesta?

Vendedor: 50 pesos.

Cliente: ¿Y qué hace?

Vendedor: Mueve las alas hacia arriba y hace más cosas, pero como no tiene pilas no lo he probado.

Cliente: Ah, pero no tiene la tapita ¿verdad?

Vendedor: pos no.

Cliente (dirigiéndose a sus hijos): No se los voy a comprar porque no se portan bien, aparte se van a ir peleando los dos como ahorita por la pistolita.

Hijo de en medio: No mami, ahorita me compras a mí otra cosa.

Cliente (dirigiéndose al vendedor): ¿Cuánto cuesta ese dinosaurio?

Vendedor: 15 pesos.

Cliente: ¿Y el carrito?

Vendedor: Ése en 15, o llévese los dos por 25 pesos

La señora pagó los tres juguetes, pero antes de irse el niño mediano le dijo: -mira mami, esta pistolita.

Y la señora como que no quería, pero preguntó cuánto costaba. Y al saber que costaba 10 pesos, le dijo a su hijo: - Te lo voy a comprar, pero yo no sé si te corren de la escuela vas a ver...

Pero el niño finalmente le dijo que mejor no quería la pistolita. ${ }^{21}$

\footnotetext{
${ }^{16}$ En el seguimiento realizado entre marzo y mayo de 2018 a una familia que se instala como "tiradito" para revender artículos que consigue en el mercado fue clara la preferencia de esta familia por adquirir juguetes, nuevos o usados, que revendían con facilidad. Y, al instalarme junto con mi hijo de siete años en un mercado, no pudimos terminar de poner el puesto sino hasta haber atendido a los clientes que se interesaron en varios de los juguetes usados que traíamos para la venta (diario de campo del 20 de marzo de 2011).

17 Grupo focal de Guadalupe (en adelante GFG), 5 de julio de 2018.

18 GFM, 13 de julio de 2018.

19 Diario de campo del 12 de mayo de 2011.

${ }^{20}$ Diario de campo de Francisco Reyes (14 de abril de 2018).

${ }^{21}$ Diario de campo de Francisco Reyes ( 14 de abril de 2018).
} 
El "hallazgo" de mercancías baratas y la habilidad para lograrlo es compartido como experiencia, y se invita a otros a compartirla, lo cual es un indicador del tipo de mensajes que se busca transmitir cuando se compran o regalan las mercancías baratas:

Cuando vamos al mercadito, hasta pasamos a la casa de mi mamá a mostrarle [lo que compramos]. O... pasamos la voz con los vecinos. Una amiga me dice:

-Ay, qué bonita tu blusa ¿dónde la compraste?

-Pues en el mercadito a 5 pesos...

—¿A poco? ¿a cuál mercadito? para ir...

-Al de acá de abajo, el que se pone desde la tarde

hasta la noche...

-Ah, me voy a dar una vuelta, a ver si encuentro... ${ }^{22}$

Los artículos adquiridos en el mercadito, así como la experiencia misma del tianguis, ratifican y recrean la práctica social de la familia, sobre todo en el sentido de que todos estamos juntos en esto, todos vamos al mercadito, todos compramos mercancías para todos, y todos estamos implicados en conseguir mercancías baratas que en principio ayudan a la economía familiar, pero que en realidad sirven para refrendar nuestros vínculos.

De acuerdo con la investigación, la ropa usada y nueva es la mercancía de fayuca que más se vende en los tianguis de Monterrey, por tal razón me detendré ahora a revisar el papel de la ropa usada en cuanto que objeto de consumo en los mercaditos.

\section{El consumo de ropa usada}

En esta sección presento a las compradoras de ropa usada y nueva en cuanto que consumidoras análogas (Leonard, 2009) que permanecen afuera, pero no excluidas, del conjunto de deseos a los que, se supone, debiera sucumbir cualquier individuo de una sociedad mercantilizada. Así, se puede consumir ropa usada y de saldos simplemente porque no se pretende, no se desea o no se tiene como expectativa adquirir mercancías nuevas y de moda típicas de la fast fashion:

hay saquitos de 150 pesos, o abrigos, que son nuevos, pero con algún defecto. Por ejemplo, compré un saco de una calidad muy buena, pero lo único que tenía es que el hilo con el que estaba encordado el ojal del brazo derecho y del izquierdo era de diferente color, uno era café y otro mostaza, pero, ¿quién se va a andar fijando en eso ${ }^{23}$

La pregunta, lanzada por una madre de familia habitante de una colonia de clase media, devela un hecho muy interesante. Para ella, "fijarse" en algún defecto en una prenda no es relevante ni para ella ni para nadie. De este modo, contradice uno de los aspectos que definen a la fast fashion. En ésta, dice Brooks (2015: 18) "la fabricación es rápida y barata, y los consumidores fácilmente pueden aprovechar colecciones asequibles... y así formar parte del último grito de la moda". Pero la informante parece no estar preocupada por este último aspecto, y más bien su adquisición de ropa usada se deriva de los otros dos aspectos de la fast fashion: es barata y está por todos lados. Y, en este caso, es el mercadito el que le da acceso a la ropa, aun y cuando ésta no sea "el último grito de la moda". En igual sentido puede entenderse que las participantes en los grupos focales, sobre todo los de ingreso bajo, acepten que buscan ropa usada por ser ésta de tallas más grandes que las de los almacenes del centro de la ciudad. ${ }^{24}$

Ahora bien, la ropa que está accesible en el tianguis es barata al igual que la ropa que se encuentra en otros almacenes mencionados por las informantes. ${ }^{25}$ Pero en el mercadito es "ropa americana", al margen de si es usada o nueva. Aunque no se asume expresamente, el hecho de que sea de Estados Unidos representa una cierta ventaja o garantía de calidad en relación sobre todo con una prenda nueva adquirida en un almacén en México (sea o no fabricada en el país):

22 GFM, 13 de julio de 2018.

${ }^{23}$ Entrevista con Norma, 23 de abril de 2018.

${ }^{24}$ La idea de fast fashion proviene de la idea de fast food, donde la baja calidad de los alimentos y la amplia disponibilidad de los mismos son características centrales. La fast fashion se refiere, entonces, a la producción masiva de ropa de baja calidad o con precios accesibles, de tal modo que mucha gente la puede comprar de forma casi rutinaria. También alude a la desechabilidad: la ropa que se compra ahora puede ser sustituida muy pronto, tan sólo porque puede comprarse otra, y no porque la anterior esté obsoleta.

${ }^{25}$ Las informantes de sector medio admitieron consumir también en almacenes como Sears, Liverpool, C\&A y El Nuevo Mundo. Las informantes de sector medio bajo, por su parte, consumen en Del Sol, Milano y Melody. Las de sector medio advirtieron que compran en aquellos almacenes sólo cuando hay ofertas. De acuerdo con la cantidad de prendas, los precios, los estilos y la dinámica de abastecimiento, se considera que todos estos almacenes forman parte de cadenas de distribución propias de la fast fashion: ropa accesible para muchos, todo el tiempo. 
GFM1: Ellos [los vendedores de los tianguis] traen saldos que... los mandan del otro lado, de Estados Unidos.

GFM3: De las fábricas.

GFM2: De las fábricas, o por decir, que ellos [los almacenes minoristas de Estados Unidos] no venden, las venden como saldos y ellos [los fayuqueros] las compran más barato y le sacan más dinero a la paca. ${ }^{26}$

De hecho, las consumidoras tienen conciencia de que muchas de las mercancías vendidas en el tianguis, en particular las usadas, provienen de Estados Unidos y, cuando es el caso de la ropa nueva, las consumidoras destacan el hecho de que tienen la etiqueta del almacén minorista del cual provienen (en la forma de saldo). Igual que los consumidores regiomontanos que hacen shopping en la frontera de Texas (Sandoval Hernández, 2012), las consumidoras de los mercaditos, algunas de las cuales también hacen shopping en la frontera de Texas, asumen que lo "americano" suele ser de mejor calidad, de distintas variedades, modelos y hasta tallas. Esta característica, la de ser "americano", puede agregarse como argumento cuando se presume aquello que se adquirió en el tianguis.

Otro rasgo del consumo en el tianguis tiene que ver con las relaciones que pueden entablarse en el lugar. En el mercadito es posible hacer amistad con un vendedor quien puede traer encargos de mercancías desde Estados Unidos, dar crédito o traer artículos que sabe interesarán a uno como cliente. Estas relaciones personalizadas son difíciles de entablar en los grandes almacenes de ropa nueva. Veamos el caso de Norma, casada, de poco más de 50 años, con tres hijos (35, 20 y 17 años), es ama de casa y vende por catálogo zapatos y cremas faciales. Cuando llegó a una de nuestras citas para visitar un tianguis me dijo, señalando la blusa y el pantalón que vestía: "mira, de mercadito" y, más adelante, casi orgullosa, afirmó: "la mayoría de la ropa de la familia viene del mercadito", estimando que 90 por ciento de la ropa que tienen la compra en el tianguis.

Norma va todos los martes al tianguis de San Antonio, en San Nicolás de los Garza. Ahí acude al local de Feliciana, vendedora de ropa usada. En cada visita, Norma gasta al menos 500 pesos, pero no sólo compra para ella: "El martes pasado le compré una blusita a Carolina [su hija], y unos pantalones blancos ipero así, la tela muy padre, se siente suavecita! A Carolina le encantaron". Y, de igual modo, la visita al mercadito se hace en familia (en este caso sobre todo con su hija) o con amistades. Antes, "cuando Carolina estaba en la secundaria”, Norma iba con la mamá de una compañera de su hija, ahora va con su amiga Nelly, "y hay otras señoras con las que me pongo a platicar en el puesto de Feliciana, algunas hasta se van a tomar un café". Además, ahí siempre se encuentra con Roberto, el amigo que le recomendó el puesto de Feliciana: "él siempre gasta de mil pesos para arriba cada que viene con doña Feliciana. Compra ropa para su esposa y toda su familia. ${ }^{27}$

\section{Conclusión}

En este artículo he mostrado que la compra de fayuca es parte de prácticas sociales que son importantes para la gente. Estas prácticas son una cuestión local en el sentido del familismo que da significado a muchas de las cosas que las personas hacen cotidianamente. La fayuca y el tianguis resultan oportunidades muy a la mano para mantenerse involucrados en tal familismo. Están a la mano tanto por la cercanía física (los tianguis están en el barrio), como por lo barato de las mercancías. Así, el tianguis y la fayuca facilitan acceder a objetos con ciertas características, en la forma de mercancías, que permiten el involucramiento en relaciones y prácticas sociales.

Aunque aquí he puesto énfasis en el sentido que las compras en el tianguis tienen para la práctica social de la familia, en realidad ésta no es la única práctica social dadora de sentido. El trabajo de campo arrojó, sobre todo para el caso de la ropa y algunos accesorios, que la construcción de la identidad individual y grupal suelen ser trascendentes también. En el tianguis se mezclan los consumidores que buscan en la ropa, tanto nueva como usada, elementos materiales funcionales para otras prácticas sociales.

Entre las montañas y los racks de ropa usada suele haber jóvenes, en particular mujeres, que buscan prendas de estilo vintage o retro. Éstas sirven para construir una imagen de autenticidad, en contraposición a las vestimentas comunes o identificadas con la fastfashion; asimismo, están aquellos, en su mayoría varones, que buscan ropa holgada y con diseños o estilos propios de las gangs o pandillas, de los raperos o cantantes de hip hop; de igual modo, están quienes buscan ropa de marcas mundialmente conocidas, con la clara perspectiva de pretender una imagen "a la moda", pero a precios económicos. Para todos ellos es muy relevante la adquisición de accesorios como cinturones, anteojos, bolsas, zapatos, calcetines,

\footnotetext{
${ }^{26}$ GFM, 13 de julio de 2018.

${ }^{27}$ Entrevista con Norma, 23 de abril de 2018.
} 
bisutería, micas para celular, calcomanías y hasta juguetes. Todo puede encontrarse en el mercadito en calidades, variedades y precios que suelen ser mejores que los de algunos almacenes minoristas.

El tianguis es, entre otros, un lugar donde, gracias a cadenas de aprovisionamiento globales (Alarcón, 2004), muchas mercancías están al alcance de los consumidores, pero aquí lo esencial ha sido destacar que, a partir del acto de adquisición (compra), esos artículos se convierten en elementos materiales de la elaboración de prácticas sociales y, con ello, de la construcción de la identidad individual y, en fin, de las relaciones sociales significativas para las personas.

\section{Fuentes}

Alarcón, Sandra

2004 "El tianguis global/La inserción de los comerciantes callejeros en las cadenas globalizadas de venta", tesis de maestría en Antropología

ARIZA, MARINA Social, Universidad Iberoamericana, México.

y ORLANDINA DE Oliveira

2004 "Universo familiary procesos demográficos", en Marina Ariza y Orlandina de Oliveira, Imágenes de la familia en el cambio de siglo, Universidad Nacional Autónoma de México, México, pp. 9-45.

Arvanitidou, Zoi y María Gasouka

2013 "Construction of gender through fashion and dressing", en Mediterranean Journal of Social Sciences, vol. 4, núm. 11, pp. 111-115.

Bourdieu, Pierre

1998 La distinción. Criterio y bases sociales del gusto, Taurus, Madrid, $597 \mathrm{p}$.

Brooks, DAVID

2015 La doble vida de los jeans. La cara oculta de la moda rápida y la ropa de segunda mano, Paidós, México, 319 p.

Duffy, Katherine, Paul Hewer

Y JULIETTE WiLSON

2012 "Granny would be proud: on doing vintage, practices and emergent socialities", en NA Advances in Consumer Research, vol. 40, pp.

Ewen, Stuart 519-525.

1991 Todas las imágenes del consumismo. La política del estilo en la cultura contemporánea, Consejo Nacional para la Cultura y las Artes/ Grijalbo, México, 597 p.

Giddens, Anthony

2003 La constitución de la sociedad. Bases para la teoría de la estructuración, Amorrortu, Buenos Aires, 412 p.

GILl, LOUIS

2009 "À l'origine des crises: surproduction ou sousconsommation?", en Carré Rouge, núm. 40, abril, pp. 43-55.

HaRVEY, DAVID

2013 El enigma del capital y las crisis del capitalismo, Akal, Madrid, 239 p.
Koca, Emine, Tuba Vural

Y FATMA KOÇ

2013 "An evaluation of consumer tendencies towards hedonistic shopping for clothes", en European Journal of Research on Education, núm. especial, Human Resource Manage-

LEONARD, ZOE ment, pp. 54-64.

2009 “Analogue(Analógico)”, en Museo NacionalCentro de Arte Reina Sofía (Colección), <https: / / www.museoreinasofia.es / coleccion / obra / analogue-analogico> [ 10 de junio de 2017].

Lichtenstein, Nelson

2006 "Wal-Mart. Un modelo para el capitalismo del siglo xxI", en Nelson Lichtenstein (coord.), Wal-Mart. El rostro del capitalismo del siglo XxI, Popular, Madrid, pp. 19-55.

Mauss, Marcel

1995 "Essai sur le don. Forme et raison de l'échange dans les sociétés archaïques", en Marcel Mauss, Sociologie et anthropologie, Quadrige/ Presses Universitaires de France, París, pp. 143-279.

Miller, Daniel

1999 Ir de compras: una teoría, Siglo xxi Editores, México, $199 \mathrm{pp}$

PARSONS, LIZ

2007 "Thompson's Rubbish theory: Exploring the practices of value creation", en E-European Advances in Consumer Research, vol. 8, pp. 390-393.

RECKWITZ, ANDREAS

2002 "Toward a theory of social practices: A development in culturalist theorizing", en European Journal of Social Theory, vol. 5, núm. 2, pp. 243-263.

Rubio Campos, Jesús

2015 "Comercio y diversión en la calle. Análisis de las estrategias de apropiación del espacio público en los mercados sobre ruedas nocturnos de Monterrey", en Camilo Contreras (coord.), Monterrey a través de sus calles. Una revisión desde las ciencias sociales, Gobierno del Estado de Nuevo León / Consejo para la Cultura y las Artes de Nuevo León/Colegio de la Frontera Norte/Consejo Nacional para la Cultura y las Artes, Monterrey, pp. 133-154.

SANDOVAl HeRnÁndeZ, EFrÉn

2012 Infraestructuras transfronterizas. Etnografía de itinerarios en el espacio social MonterreySan Antonio, Centro de Investigaciones y Estudios Superiores en Antropología Social/Colegio de la Frontera Norte, México, 346 p.

Stebbins, Robert A.

2006 "Shopping as leisure, obligation and community”, en Leisure/Loisir, vol. 30, núm. 2, pp. 467-474.

Strasser, Susan

2006 "De Woolworth a Wal-Mart. Comercio masivo y la cambiante cultura del consumo", en Nelson Lichtenstein (coord.), Wal-Mart. El rostro del capitalismo del siglo XXI, Popular, Madrid, pp. 57-89.

WARDE, Alan

2005 "Consumption and theories of practice", en Journal of Consumer Culture, vol. 5, núm. 2, pp. 131-153. 